\title{
Antiadhesive Properties of Biological Surfaces Are Protective against Stimulated Granulocytes
}

\author{
Jorg Fehr, René Moser, David Leppert, and Peter Groscurth \\ Department of Medicine, Section of Hematology, and Department of Anatomy, Division of Cell Biology, \\ University of Zurich, $\mathrm{CH}-8091$ Zurich, Switzerland
}

\begin{abstract}
Despite the fact that a series of endogenous and exogenous inflammatory mediators are potent activators of circulating granulocytes, damage of vascular endothelium, a primary target tissue, is a rather unusual event in systemic inflammatory states. Since mediator-induced neutrophil hyperadhesiveness on plastic tissue culture dishes is invariably accompanied by intense release of lysosomal granule constituents and respiratory burst activation, thus representing a powerful model to investigate neutrophil cytotoxic states, comparative studies with neutrophils suspended in autologous plasma in the presence or absence of $N$-formyl-Met-Leu-Phe $(2.5 \mu M)$, the most potent adhesion inducer, were performed on different biologic surfaces. On optimally adherent closed monolayers of cultured endothelial cells or fibroblasts we observed poor stimulation of adhesion as well as minimal granule release and hexose monophosphate pathway activation. Functional behavior of neutrophils on single molecular components of basal laminas such as fibronectin and collagen (type IV) coats was intermediate, with positive adhesion promotion but markedly reduced metabolic activation. When tested on endothelial cell-derived extracellular matrices, neutrophils again showed functional nonresponsiveness to $\boldsymbol{N}$ formyl-Met-Leu-Phe. Scanning electron microscopy revealed an impressive congruency between the degree of cellular spreading and metabolic activation in the presence of $\mathbf{N}$-formylMet-Leu-Phe, with maximally flattened neutrophils on plastic vs. nonspread, polarized cells on monolayers. Identical results were obtained by using other adhesion inducers such as complement-activated plasma or endotoxin. Lack of cell injury by $\boldsymbol{N}$-formyl-Met-Leu-Phe-exposed neutrophils was corroborated by the absence of tracer release from [ ${ }^{111}$ In]tropolonate-labeled endothelium. These results indicate that biologic surfaces possess antiadhesive properties that protect them from cytotoxic damage by stimulated angry phagocytes.
\end{abstract}

\section{Introduction}

Research performed primarily over the last 10-15 yr has identified a powerful cytotoxic armamentarium of human neutrophils. Upon activation by particle phagocytosis, circu-

Portions of this work were published in abstract form in 1984. Clin. Res. 32:313.

Address correspondence to Dr. Fehr, Department of Medicine, CH 5, University Hospital, CH-8091 Zurich, Switzerland.

Received for publication 13 December 1984 and in revised form 20 March 1985.

J. Clin. Invest.

(C) The American Society for Clinical Investigation, Inc. 0021-9738/85/08/0535/08 $\$ 1.00$

Volume 76, August 1985, 535-542 lating or bound immune complexes, and endotoxin as well as a series of other soluble stimuli (1), neutrophils generate reactive oxygen metabolites (2) and discharge lysosomal components $(3,4)$. Since vascular endothelial cells are a primary target for systemically or locally activated neutrophils, in vitro models suitable to study neutrophil-endothelium interaction have become an important experimental tool. However, results obtained thus far with such models allow no definite and uniform conclusions, and it remains unclear under what circumstances and conditions neutrophils may damage endothelial cells and, if they do, what mechanisms are mainly responsible for such damage. Whereas initial studies pointed to an oxygen metabolite-dependent $(5,6)$ or protease-dependent (7) endothelial cell alteration induced by stimulated neutrophils, more recent observations demonstrated the lack of damage to endothelial cell monolayers, even after prolonged exposure to phorbol myristate acetate-activated granulocytes (8, 9). A thorough analysis of the role of the glutathione redox cycle of cultured endothelial cells led to the conclusion that endogenous antioxidant defense mechanisms are protective against aggressive neutrophils (9).

On the one hand, soluble mediator-induced neutrophil hyperadhesiveness on plastic tissue culture dishes is invariably accompanied by intense release of lysosomal granule constituents and respiratory burst activation (10-13), representing a powerful model to investigate neutrophil cytotoxic states; on the other hand, endothelial vascular damage seems to be a rather unusual event in systemic inflammatory states, suggesting that protective mechanisms might indeed be operative in vivo. Therefore, comparative studies with neutrophils suspended in autologous plasma in the presence or absence of what in our hands is the most potent adhesion inducer, the $N$-formylpeptide f-Met-Leu-Phe (fMLP), ${ }^{1}$ were performed on different biological surfaces (cultured endothelial cells and fibroblasts, fibronectin, collagen, and extracellular matrix).

\section{Methods}

Preparation of cultured cells. Endothelial cells were obtained from human umbilical cord veins by the method of Jaffe et al. (14). The cells were grown in Medium 199 (Gibco Laboratories, Glasgow, Scotland) supplemented with $20 \%$ pooled heat-inactivated $\left(56^{\circ} \mathrm{C}, 30\right.$ min) human serum, penicillin (100 U/ml; Gibco Laboratories), and streptomycin $(100 \mu \mathrm{g} / \mathrm{ml}$; Gibco Laboratories) and buffered with 15 mM Hepes (Calbiochem-Behring Corp., La Jolla, CA) at pH 7.55. For optimal growth stimulation, the thedium was constantly enriched with L-glutamin ( $2 \mathrm{mM})$, endothelial cell growth factor from bovine hypothalamus (15 $\mu \mathrm{g} / \mathrm{ml}$; Collaborative Research, Inc., St. Waltham, MA;

1. Abbreviations used in this paper: $\mathrm{B}_{12}-\hat{\mathrm{B}} \mathrm{P}$, vitamin $\mathrm{B}_{12}$ binding protein; ECM, endothelial extracellular matrix; IMLP, $N$-formyl peptide f-Met-Leu-Phe; HMP, hexose monophosphate pathway; SEM, scanning electron microscopy. 
15), and sodium heparin $(90 \mu \mathrm{g} / \mathrm{ml}$; Novo Industries, Copenhagen, Denmark; 16). Endothelial cells suspended in this medium were seeded in $25-\mathrm{cm}^{2}$ flasks (Corning Glass Works, Corning Science Products, Corning, NY). Primary cultures were grown to confluence at $37^{\circ} \mathrm{C}$ in a humid $5 \% \mathrm{CO}_{2} / 95 \%$ air environment and split at a 1:3 ratio. Final monolayers used to study neutrophil-endothelium interactions were prepared on $10 \times 35-\mathrm{mm}$ tissue culture dishes (No. 3001; Falcon Labware, Becton, Dickinson \& Co., Oxnard, CA) or, for part of scanning electron microscopy (SEM) studies and the endothelial "'In release assay, on 15-mm round Thermanox plastic coverslips (Lux; Miles Scientific Div., Miles Laboratories Inc., Naperville, IL) kept on the bottom of 16-mm plastic culture wells (Cluster 24; Costar, Data Packaging Corp., Cambridge, MA). All culture surfaces (flasks, dishes, and coverslips) were coated with fibronectin to improve growth and adhesion of endothelial cells (15). Coating was accomplished by incubating such surfaces at room temperature for $\mathbf{4 5} \mathrm{min}$ with human plasma fibronectin (Collaborative Research, Inc.; 99\% pure when checked by gel electrophoresis and immunological techniques) solubilized in Medium 199 at a concentration of $3 \mu \mathrm{g} / \mathrm{cm}^{2}$, followed by three washes with phosphate-buffered saline to remove nonadherent protein. All monolayers used in this study were completely confluent (Fig. $1 A$ ), as routinely checked by phase-contrast microscopy, and were in their fourth passage. (Control experiments using primary cultures showed identical results.) Endothelial cell identification was accomplished by the detection of Factor VIII antigen with indirect immune fluorescence technique $(14,17)$ and of Weibel-Palade bodies in transmission electron microscopy and showed only rare contamination by other cells (perhaps smooth muscle cells) (17).

For experiments involving neutrophil-fibroblast interaction, normal human skin fibroblasts were kindly provided by Dr. Beat Steinmann, Kinderspital, Zurich. Completely covering cell layers were cultured in the 4th-12th passage under identical conditions except that growth factor and heparin were not added to the culture medium.

Preparation of subendothelial extracellular matrix (ECM). Confluent endothelial cell monolayers on $10 \times 35$-mm tissue culture dishes (functional studies) or on Thermanox coverslips (morphologic studies) were maintained in culture for an additional 6-10 d to produce a close layer of ECM. Culture dishes coated with ECM were prepared as previously published (18): endothelial monolayers were first lysed with distilled water and then exposed to $0.5 \% \mathrm{NH}_{4} \mathrm{OH}$ in distilled $\mathrm{H}_{2} \mathrm{O}$ for $5 \mathrm{~min}$ at room temperature; the adherent matrix was washed five times with phosphate-buffered saline. As shown in Fig. $1 B$, the insoluble ECM remained firmly attached to culture dishes/coverslips. In some experiments, neutrophil-ECM interaction was studied after ECM had been preincubated with antifibronectin antibodies and with $F\left(a b^{\prime}\right)_{2}$ fragments of such antibodies (Cappel Laboratories, Cochranville, PA); after preincubation for $30 \mathrm{~min}$ at $20^{\circ} \mathrm{C}$ and before adding the neutrophils suspended in plasma, the ECM-coated culture dishes were washed four times with phosphate-buffered saline.

Preparation of protein coats for neutrophil adherence. To study neutrophil adherence on protein-coated surfaces, human fibronectin was adsorbed to culture dishes/coverslips as described above for endothelial cell culturing. Human collagen type IV purified to homogeneity was kindly provided by Dr. Bernhard Odermatt, Dept. of Pathology, University of Zurich. After solubilization in $\mathbf{0 . 0 2} \mathrm{M}$ acetic acid, 1-ml aliquots containing $20 \mu \mathrm{g} / \mathrm{ml}$ of collagen were incubated in $10 \times 35-\mathrm{mm}$ culture dishes for $45 \mathrm{~min}$ at room temperature followed by three washes with phosphate-buffered saline. The existence of a homogeneous protein surface coat was verified by SEM (positive scratch phenomenon). For comparative studies with albumin coating, dishes were preincubated with electrophoretically pure albumin $(5 \mathrm{mg} /$ ml phosphate-buffered saline; Behring-Werke AG, Marburg/Lahn, FRG) for $\mathbf{4 5} \mathrm{min}$ and washed identically.

Preparation of neutrophil suspension and plasma. Venous blood from healthy human donors was collected into $60-\mathrm{ml}$ plastic syringes containing preservative-free sodium heparin $(20 \mathrm{U} / \mathrm{ml}$ blood; Novo Industries). Neutrophils were separated and resuspended in autologous heat-inactivated plasma ( $3 \mathrm{U}$ heparin/ml) exactly as described (12).
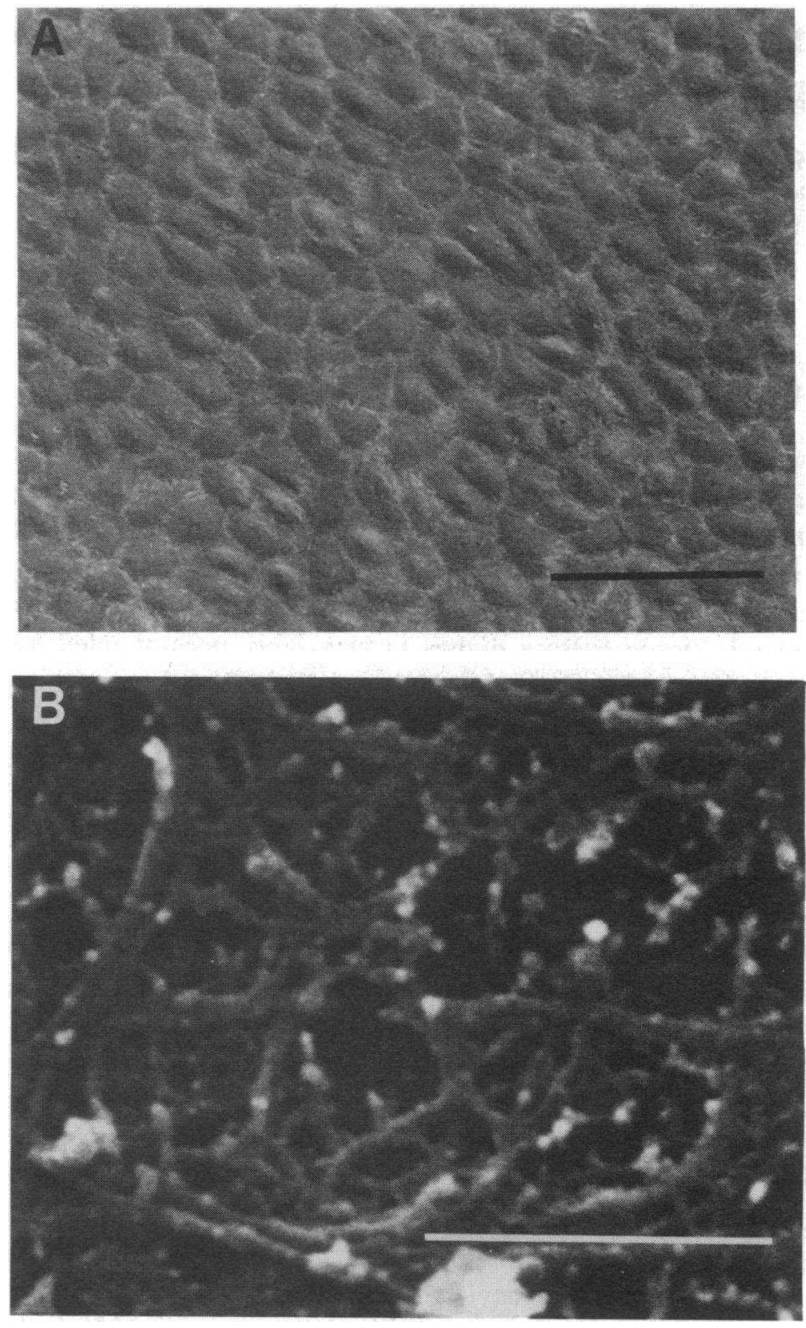

Figure 1. (A) Human umbilical vein endothelial cell monolayer at confluence as used for the neutrophil studies. The scanning electron micrograph shows a mature monolayer with closely packed polygonal cells on a 35-mm tissue culture dish (ethanol dehydration). Scale bar, $100 \mu \mathrm{m}$. (B) Structure of denuded ECM. The scanning electron micrograph shows appearance of an ECM layer on a Thermanox plastic coverslip. A confluent endothelial monolayer was maintained in culture for an additional $\mathbf{8} \mathbf{d}$ before the cells were lysed. Scale bar, $1 \mu \mathrm{m}$.

Basal and stimulated neutrophil adherence and concomitant granule constituent release and hexose monophosphate pathway (HMP) activation of cells on different surfaces. Neutrophil adhesion on plain plastic surface, protein-coated surfaces, or completely closed cell layers that had been washed four times with buffer solution was assessed as previously outlined $(12,19)$. Briefly, 1-ml aliquots of neutrophil suspensions $\left(4 \times 10^{6}\right.$ cells $/ \mathrm{ml}$ of heat-inactivated plasma) were incubated in $10 \times 35-\mathrm{mm}$ culture dishes for $40 \mathrm{~min}$ at $37^{\circ} \mathrm{C}$ and $100 \%$ humidity/ $5 \% \mathrm{CO}_{2}$. Immediately before plating, the adhesion stimulus fMLP (Bachem AG, Bubendorf, Switzerland) was added at a final concentration of $2.5 \mu \mathrm{M}$ (10); dilution by stimulus solution or control solvent (phosphate-buffered saline) was $1 \%$ by volume. Addition of AMLP after cells had already settled onto surfaces $(10 \mathrm{~min})$ did not alter the results. After incubation, the dishes were washed thoroughly and the nonadherent neutrophils were removed by carefully passing the culture dishes three times through an air-medium interface sequentially in four beakers containing phosphate-buffered saline at room temperature. 
Detachment of endothelial or fibroblast cell layers was never observed. The dishes were dried at $4^{\circ} \mathrm{C}$. The number of adherent neutrophils was quantified by measuring their myeloperoxidase content and was expressed as the percentage of initially applied cells (19). No myeloperoxidase was detectable in endothelial cells or fibroblasts, and myeloperoxidase-derived adherence was verified by phase-contrast microscopy. Vitamin $B_{12}$ binding protein $\left(B_{12}-B P\right)$, a sensitive marker for concomitant release of secondary granule constituents, was measured by the relative absorption of $\left[{ }^{57} \mathrm{Co}\right] B_{12}$ (12). To calculate the fraction of total cellular $\mathrm{B}_{12}-\mathrm{BP}$ released, neutrophils in heat-inactivated plasma were frozen-thawed three times after adding $0.5 \%$ Triton X-100. Basal and stimulated HMP activity with neutrophils incubated on culture dishes was determined by measuring the generation of ${ }^{14} \mathrm{CO}_{2}$ from [1$\left.{ }^{14} \mathrm{C}\right] \mathrm{glucose}(12)$ and was assessed concomitantly with the adhesion/ granule release experiments with the same cell batches in triplicates under completely identical conditions.

Determination of endothelial damage by "'In release assay. Endothelial cell monolayers cultured on Thermanox coverslips (see above) were labeled with [11'In]tropolonate just before they were used for neutrophil interaction studies. The labeling procedure was adopted from a published technique (20) that is an established method for neutrophil labeling in our laboratory: tropolone (SERVA Feinbiochemica Gmbh \& Co., Heidelberg, FRG) dissolved in phosphate-buffered saline was added at a final concentration of $0.2 \mu \mathrm{M}$ to Medium 199/ $20 \%$ human serum; after addition of [ $\left.{ }^{111} \mathrm{In}\right] \mathrm{Cl}_{3}(10-20 \mu 1$ in $0.04 \mathrm{M}$ $\mathrm{HCl}, 50 \mathrm{mCi} / \mathrm{ml}$; New England Nuclear, Boston, MA) $50 \mu \mathrm{l}$ of this solution containing 2-5 $\mu \mathrm{Ci}{ }^{11}$ 'In was pipetted into each well and incubated for $10 \mathrm{~min}$ at $37^{\circ} \mathrm{C}$. After four washes with Medium 199 resulting in $10 \%$ retention of label by the endothelium, $500 \mu \mathrm{l}$ of neutrophils suspended in heat-inactivated plasma $\left(4 \times 10^{6}\right.$ cells $\left./ \mathrm{ml}\right)$ was added to each well in the presence or absence of $2.5 \mu \mathrm{M}$ AMLP. Incubations continued at $37^{\circ} \mathrm{C}$ for $2-4 \mathrm{~h}$. After this time, $250 \mu \mathrm{l}$ of supernates was assessed for radioactivity (gamma counter) and maximum release was determined from wells incubated in $0.5 \%$ Triton $\mathrm{X}$ 100 (Calbiochem-Behring Corp.) that released $>95 \%$ of the cell layer counts into the supernatant. As an alternative method for measuring II'In release from endothelium, coverslips were removed after the final incubation, washed as outlined for quantification of neutrophil adherence, and assayed for retention of "I"In activity.

Morphology of neutrophil-surface interaction assessed by SEM. Neutrophils on plain plastic surfaces, protein coats, or closed cell layers in the presence or absence of AMLP were incubated and washed as outlined for the adhesion studies. They were prepared for SEM by fixation with $2.5 \%$ glutaraldehyde in $0.1 \mathrm{M}$ cacodylate buffer (320 mosM/liter, $\mathrm{pH} 7.22$ ), dehydration in acetone or ethanol, and critical point drying (21). Specimens mounted on aluminum stubs were sputter coated with gold $(20 \mathrm{~nm})$ or gold-palladium $(70 \mathrm{~nm})$ using sputter pulse control. Observations were made on a JSM-25S (JEOL Ltd., Tokyo, Japan) or an SEM model 505 (Philips Electronic Instruments, Inc., Mahwah, NJ) microscope.

\section{Results}

As depicted in Fig. 2 (dashed bars) and published earlier (10, 11), a supraoptimal concentration of AMLP added to cells suspended in neat heat-inactivated plasma induced strong and persistent neutrophil hyperadhesiveness on plastic tissue culture dishes that was accompanied by intense respiratory burst activation (HMP activation) and secondary granule constituent release $\left(B_{12}-B P\right.$ release). In contrast, when neutrophils were layered over a closed endothelial monolayer under identical conditions, only inconspicuous stimulation of this cell function was observed (black bars). According to our experience, intense surface contact accompanied by cell spreading is a necessary prerequisite for prolonged and vigorous neutrophil activation in the absence of cytochalasin B $(10,12)$. Therefore, these

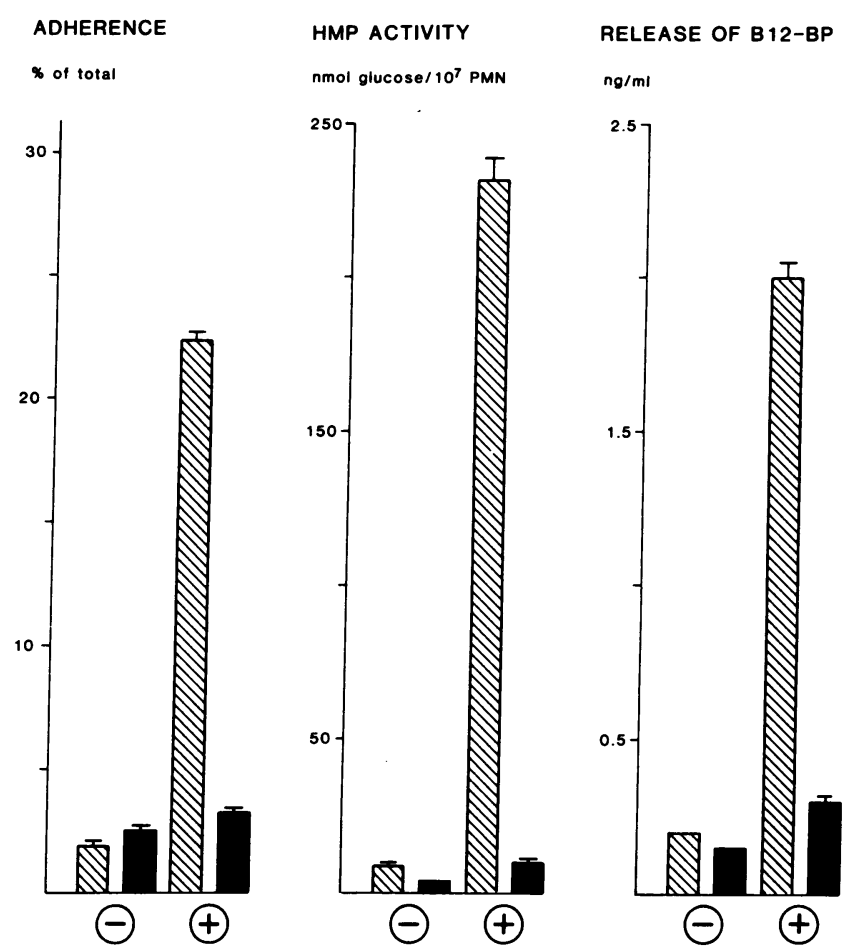

Figure 2. Adherence and functional activation of neutrophils on plastic tissue culture dishes (dashed bars) and endothelial cell monolayers (black bars). $(\Theta)$, Basal values; $(\odot)$, values in the presence of 2.5 $\mu \mathrm{M}$ (MLP. The fraction of total cellular $\mathrm{B}_{12}-\mathrm{BP}$ released in the presence of $\mathrm{AMLP}$ was, on culture dishes, $42 \pm 1 \%$, on endothelial cell layers, $6 \pm 0.4 \%$. Bars denote mean \pm SD of triplicate determinations (SD $<1 \%$ of mean are not drawn). Experiments were repeated three times with different batches of neutrophils and endothelial cells and showed congruent results. PMN, polymorphonuclear leukocyte.

unexpected findings on the endothelial surface were checked morphologically. As made evident in Fig. 4, $A-C$, morphologic appearance and state of metabolic activation of neutrophils were closely linked cellular events: the apparently surfacedependent reaction pattern of the phagocytes, rather than the concentration of the soluble mediator by itself, determined induction of a hyperactivated state. Thus, neutrophils settled on endothelial cells remained inert and retained a polarized configuration despite the presence of supraoptimal concentrations of fMLP. To see whether such antiadhesive properties were tissue type specific, identical experiments were performed on completely covering fibroblast cell layers, and again the behavior of the same neutrophil batches was controlled simultaneously on plain tissue culture dishes. As shown in Fig. $3 \mathrm{~A}$, congruent neutrophil nonresponsiveness to fMLP was observed, with cells remaining polarized (not shown). To explore the possible role of soluble inhibitors, fMLP-stimulated neutrophils were incubated on endothelial cell layers for $\mathbf{4 0} \mathrm{min}$ and then transferred to plain culture dishes: adhesion and metabolic activation of these neutrophils was very similar to that of cells added primarily to native dishes (data not shown).

In a following step, we sought models that would allow us to study neutrophil adhesion/activation behavior on denuded vessel surfaces (basal membranes). Adhesion and metabolic activation of neutrophils on culture dishes coated with single molecular components of basal membranes was tested. The 
A

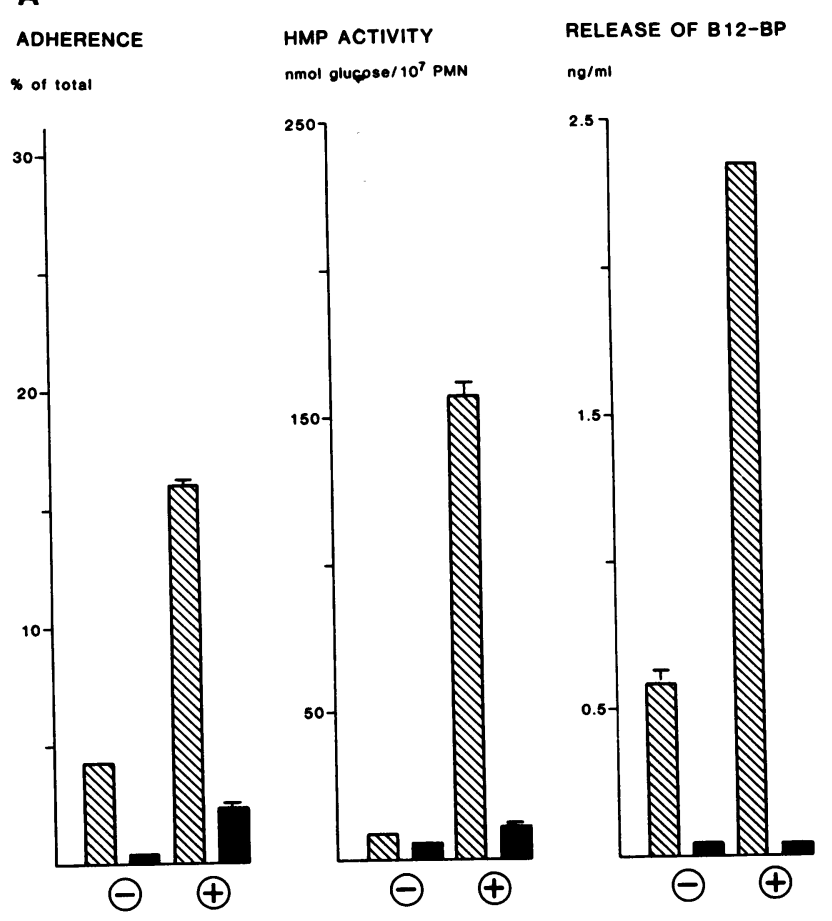

B

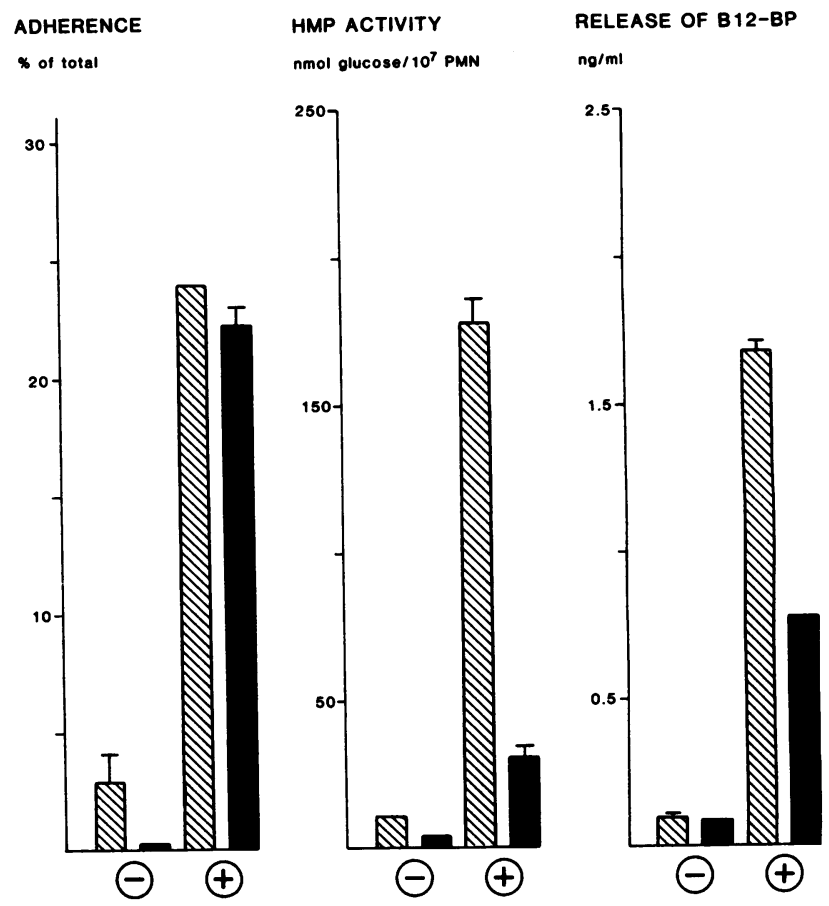

C

ADHERENCE

Xof total

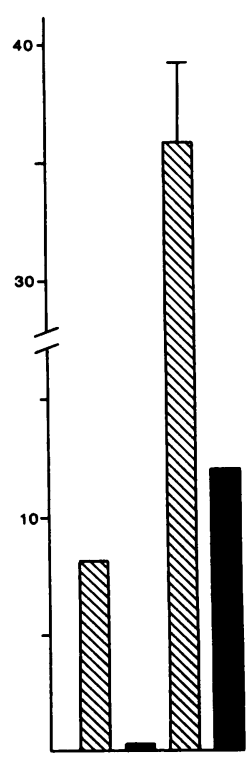

$\ominus \oplus$
HMP ACTIVITY

nmol glucose/ $10^{7}$ PMN

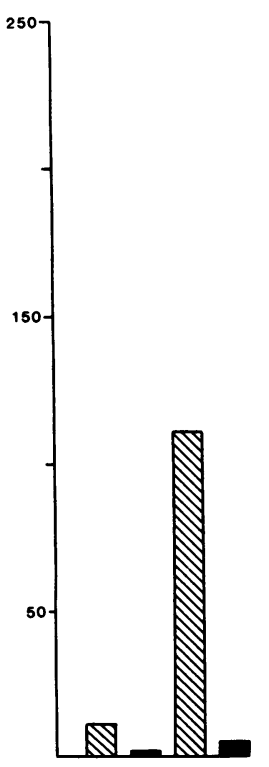

$\oplus$
RELEASE OF B12-BP

$n g / m 1$

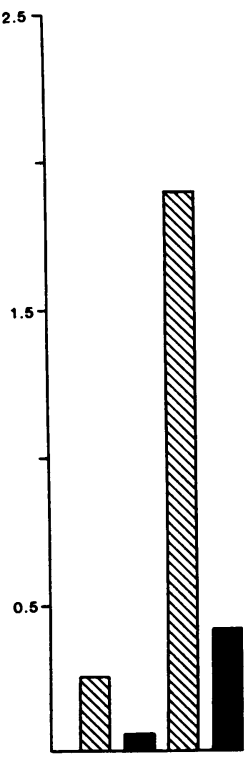

$\ominus \oplus$

Figure 3. Adherence and functional activation of neutrophils on plastic tissue culture dishes (dashed bars) and on different biological surfaces (black bars). $(A)$ Closed human fibroblast cell layers; $(B)$ fibronectin-coated culture dishes; $(C)$ collagen type IV-coated culture dishes; and $(D)$ extracellular matrix-coated culture dishes. $\Theta$, Basal

D
ADHERENCE

* of total

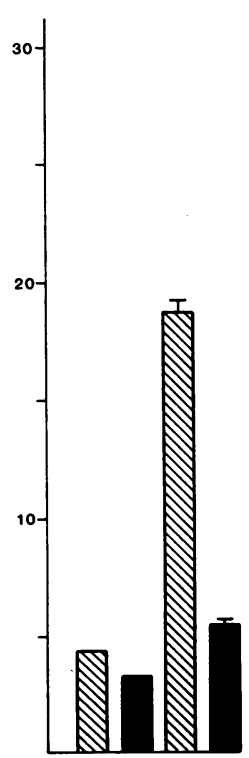

$\Theta$

$\oplus$
HMP ACTIVITY

nmol glucose $/ 10^{7}$ PMN

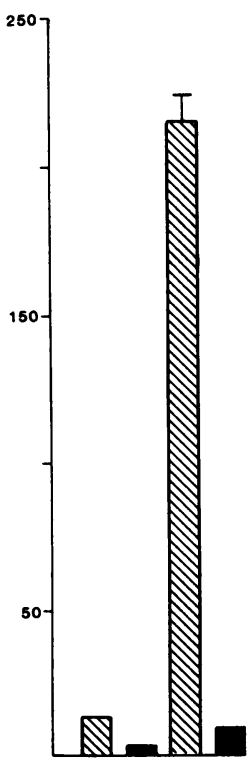

$\ominus \oplus$
RELEASE OF B12-BP

$n g / m l$

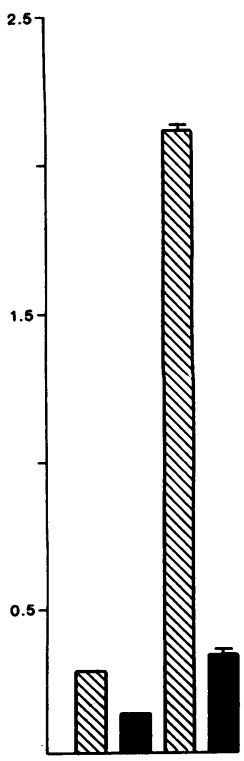

$\Theta \quad \oplus$ values; $\odot$, values in the presence of $2.5 \mu \mathrm{M}$ fMLP. Bars denote mean \pm SD of triplicate determinations (SD $<1 \%$ of mean are not drawn). Experiments were repeated at least twice showing congruent results. PMN, polymorphonuclear leukocyte. 

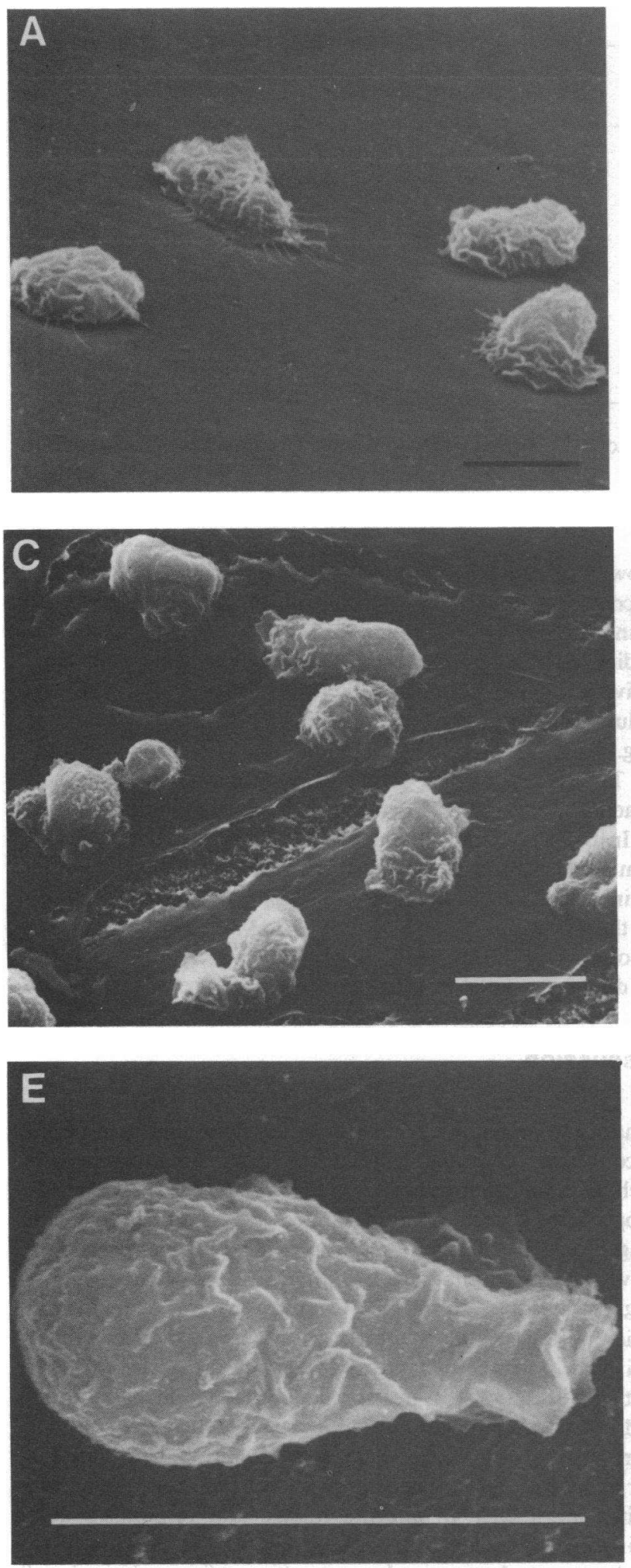

Figure 4. Scanning electron micrographs of neutrophils on different surfaces. The suspension medium for all preparations was heat-inactivated plasma, and fixation was performed after incubation for $\mathbf{4 0}$ min at $37^{\circ} \mathrm{C}$. Scale bars, $10 \mu \mathrm{m}$. (A) On plain tissue culture dishes, unstimulated neutrophils are maintaining a polarized configuration. $(B)$ In the presence of $2.5 \mu \mathrm{M}$ fMLP, neutrophils on the plastic surface are highly spread. $(C)$ On confluent endothelial cell monolayers, neutrophils are maintaining a round to polarized configuration despite the presence of $2.5 \mu \mathrm{M}$ fMLP. The fissures in the endothelial
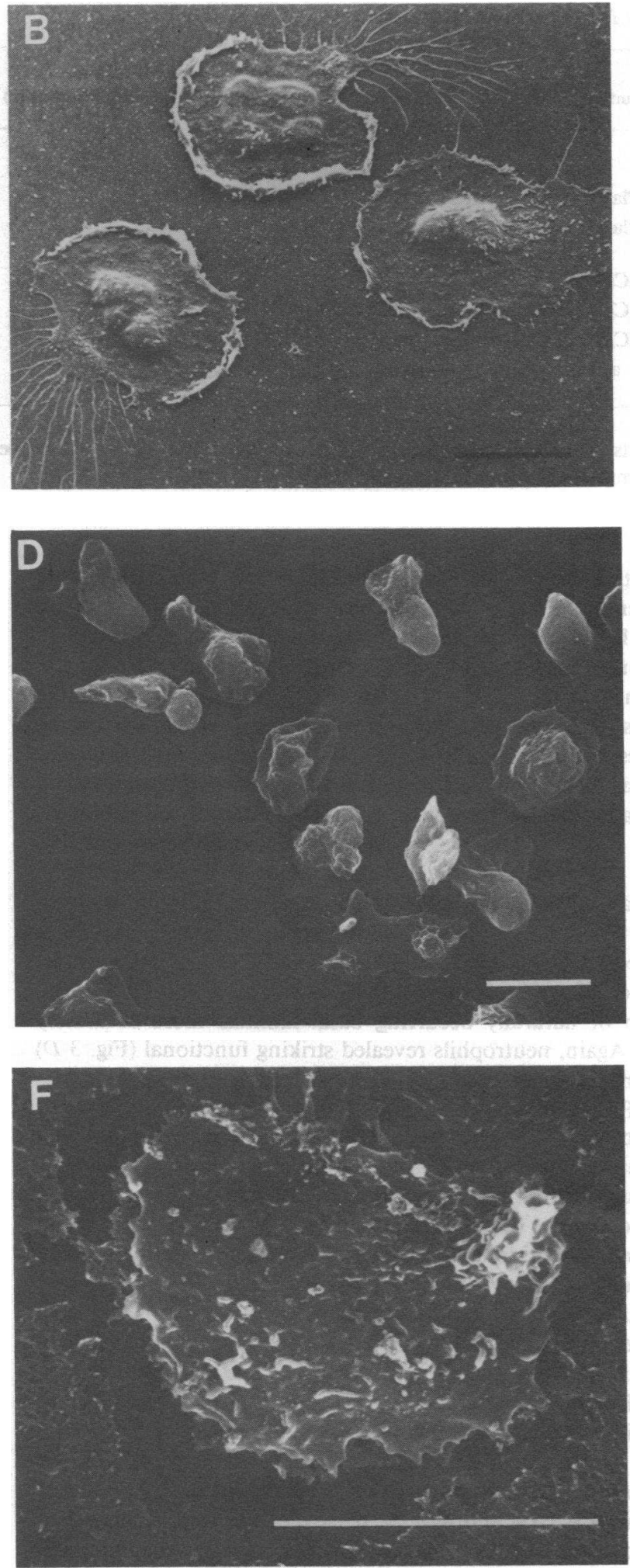

cell monolayer are fixation artifacts not observed in phase-contrast microscopy. $(D)$ On fibronectin-coated surfaces, neutrophils in the presence of $2.5 \mu \mathrm{M}$ AMLP are polarized or only incompletely spread. $(E)$ On denuded endothelial extracellular matrices, neutrophils in the presence of $2.5 \mu \mathrm{M}$ AMLP remain round or polarized, and no spreading is observed. $(F)$ On extracellular matrices that have been preincubated with antifibronectin antibodies, the vast majority of neutrophils develop a highly flattened appearance ("immuneadherence"). 


\begin{tabular}{|c|c|c|c|}
\hline Surface & $\begin{array}{l}\text { Neutrophil adhesion } \\
\text { (percentage of adherent cells) }\end{array}$ & $\begin{array}{l}\text { Granule content liberation } \\
\text { (percentage of total } \mathrm{B}_{12}-\mathrm{BP} \text { released) }\end{array}$ & HMP activity \\
\hline & & & nmol glucose $/ 10^{7}$ cells \\
\hline Plastic culture dish & $5.9 \pm 0.3$ & $7.8 \pm 0.4$ & $9.5 \pm 0.2$ \\
\hline Plastic culture dish + fMLP $(1 \mu \mathrm{M})$ & $40.0 \pm 1.0$ & $50.1 \pm 1.2$ & $94.5 \pm 2.0$ \\
\hline ECM & $5.3 \pm 0.1$ & $6.5 \pm 0.2$ & $7.5 \pm 0.3$ \\
\hline ECM + antifibronectin antibodies* & $46.1 \pm 0.5$ & $42.2 \pm 0.8$ & $68.7 \pm 2.0$ \\
\hline $\begin{array}{l}\mathrm{ECM}+\mathrm{F}(\mathrm{ab})_{2} \text { fragments of } \\
\text { antifibronectin antibodies* }\end{array}$ & $8.2 \pm 0.6$ & $6.5 \pm 0.8$ & Not done \\
\hline
\end{tabular}

Results are means \pm SD of triplicate determinations. For further details see Methods. * Highest antibody dilution (1:80) that produced continual maximal adhesion.

results obtained with cells on fibronectin-coated dishes are presented in Fig. $3 B$ and demonstrate a functional response that lies somewhere between the findings obtained on plain culture dishes and whole cell monolayers: whereas adhesion promotion by IMLP did occur, HMP activation and granule release was markedly reduced when compared with uncoated dishes. Regarding morphology, the cell shapes on fibronectin appear in Fig. $4 \mathrm{D}$ and show a predominance of polarized and partially spread neutrophils; complete flattening did not occur. Data obtained on collagen type IV-coated dishes are similar, with lowered adhesion induction and even less metabolic activation (Fig. $3 C$ ); fully spread cells were again not encountered (not shown). Neutrophils were also tested on dishes coated with endothelial cell-derived ECM (Fig. 1 B), a model surface that reflects organization and supramolecular composition of naturally occurring basal laminas more accurately (22). Again, neutrophils revealed striking functional (Fig. $3 \mathrm{D}$ ) and morphological (Fig. $4 E$ ) nonresponsiveness to high dose IMLP on this biologic surface.

In view of these findings, one might assume that any protein coating of the plastic culture dish will decrease fMLPinduced neutrophil hyperadhesion, spreading, and activation. However, one must recognize that we worked with a full plasma system, thus, most physiologic plasma coating allowed for full activation of neutrophils on plastic, whereas, under identical medium conditions, fMLP activation was impeded on cell monolayers and ECM. To underline the specificity of the antiadhesive properties of biological surfaces more clearly, fMLP stimulation of neutrophils was also performed on albumin-coated dishes. Adhesion in the presence of AMLP (2.5 $\mu \mathrm{M})$ amounted to $22.5 \pm 0.9 \%$ on uncoated and $24.7 \pm 1 \%$ on precoated dishes; the corresponding results for $\mathrm{B}_{12}-\mathrm{BP}$ liberation revealed $54 \pm 3 \%$ and $47 \pm 2 \%$ release of the total cellular $B_{12-}$ BP content, respectively (mean $\pm \mathrm{SD}, n=3$ ). Furthermore, albumin coating did not change the flattened cell morphology (spreading was identical to that seen in Fig. $4 \mathrm{~B}$ ).

We discovered, after testing other granulocyte adhesion inducers such as complement (inulin)-activated plasma (13) and endotoxin (12) under identical conditions, that neutrophil behavior on biologic surfaces was not different from the data obtained with IMLP.

Because an objection could be made that our assay system shows a general inherent inability to detect neutrophil adhesion to coated surfaces, a positive control situation was sought. We found that by preincubating ECM with antifibronectin antibodies, tight adhesion, granule content liberation, and HMP activation could indeed be observed (Table I). This activated cellular state was expressed by highly flattened neutrophils (Fig. $4 F$ ).

To study a further aspect of neutrophil-endothelium interaction, we labeled endothelial cell monolayers with [ ${ }^{111}$ In]tropolonate and then exposed them to native or fMLPstimulated neutrophils to detect possible cell damage revealed by increased label release. After an incubation time of up to 4 $\mathrm{h}$, the spontaneous release was $4.1 \pm 0.5 \%$ (mean $\pm \mathrm{SE}$ ) and amounted to $3.0 \pm 0.5 \%$ in the presence of neutrophils, with no difference noted in the presence or absence of fMLP.

\section{Discussion}

It has become a popular view that heavily armed neutrophils, once they are activated, will damage neighboring target tissues such as endothelial cells $(5,6)$. This model has been broadly adopted to explain inflammatory vascular damage such as lung injury in the adult respiratory distress syndrome (23). However, our findings clearly indicate that such a view is fragmentary and simplistic. Contrary to our expectations, which were based on experience with the induction of a highly activated, potentially cytotoxic state of granulocytes on tissue culture dishes (10-13), neutrophils layered on firmly attached and closed endothelial cell monolayers remained strikingly inert when exposed to identical soluble stimuli. Corroborating our belief that tight surface adhesion and spreading are prerequisites for neutrophil enzyme release and respiratory burst activation, this state of nonresponsiveness was accompanied by loose attachment and preservation of a polarized cell configuration that is characteristic for metabolically unstimulated neutrophils. While, phenomenologically, these data are rather self-explanatory, the discrepancies between our and studies reported earlier are more difficult to explain. We consider the following points to be most relevant: Firstly, cell membrane interactions may depend heavily on environmental conditions, a contention that sounds plausible but has not 
been respected in past in vitro studies. Thus, in protein-poor and lipoprotein-free buffer solutions, physicochemical membrane contact properties may be rather different than under plasma environmental conditions. Secondly, some of the earlier studies may have been performed with incomplete or suboptimally attached cell monolayers. Thirdly, contamination, e.g., by viruses (24) or mycoplasma (25), has been shown to alter cell surface properties with respect to interacting cells. To avoid a further misunderstanding, a distinction must be made between "low affinity adhesion," a prerequisite for phagocyte movement on plain surfaces (26), and "high affinity adhesion," that is, the type of (hyper-) adhesion described in the present study which is related to the termination of locomotion of a highly reactive cell (10-13). While such a distinction is easily made in theoretical terms, it may be difficult to define on practical grounds. Our findings, however, in concomitant morphologic and functional studies justify the assertion of such distinct types of phagocyte adhesion.

It is clear, for the following reasons, that both of our parameters, which allowed the detection of granulocyte activation, are but indirect indicators of a potentially cytotoxic state in neutrophils: $(a)$ we had to measure HMP stimulation because superoxide release cannot be measured in the presence of plasma (27) (however, by assaying HMP activity, no substantial oxygen radical production nor respiratory burst activation should go undetected $[28,29])$. (b) With respect to $B_{12^{-}}$ $B P$ release, this assay is, in our hands, the most sensitive available marker for secondary granule content liberation. Nevertheless, possible endothelial damage in the presence of fMLP-exposed neutrophils was also assessed directly by the ${ }^{111}$ In release assay whose results confirm the lack of substantial cell layer injury.

Although antiadhesive properties of cell membranes are obviously not tissue type specific because the findings on fibroblast layers were congruent, essentially similar data obtained in experiments performed with protein (fibronectin, collagen type IV) and, more important, with ECM-coated dishes suggest that our observations belong to a more general biologic principle. From a teleological point of view, this principle might be listed with other already known mechanisms operative in the antiinflammatory self-defense of the body such as the action of endogenous scavengers and antiproteases and, most recently defined, the antioxidative system of endothelial cells (9). Because metabolic stimulation of neutrophils by soluble mediators rarely occurs while these cells are in suspension $(12,13)$, the antiadhesive properties of essential tissue structures permit neutrophils, even when they are surrounded by inflammatory mediators, to reach a focus of microbial invasion without previously causing much injury to the host on their trip from the blood vessel to the focus.

Whether antiadhesive protection might collapse when activated neutrophils encounter cellular or interstitial surfaces that have been altered by foregoing injurious stimuli (30) remains to be determined. Furthermore, our unpublished observations of neutrophil adhesion induction, burst activation, and enzyme release by fMLP on closed layers of certain cultured human tumor cell lines (Ewing sarcoma) indicate that antiadhesive properties are related to distinct cell membrane characteristics whose definition may help to explain why cell membranes and interstitial tissue layers represent not only a physical but also a functional barrier to angry phagocytes.

\section{Acknowledgments}

The authors are grateful to Gabi Gitzelmann and Ursi Drotschmann for their excellent technical assistance. They also thank Dr. S. Geroulanos, K. Marquardt, and the EMDO Stiftung for providing the technical equipment to perform part of the SEM studies.

This work was supported in part by the Swiss National Science Foundation grant 3.823.81.

\section{References}

1. Weissmann, G., J. E. Smolen, and H. M. Korchack. 1980. Release of inflammatory mediators from stimulated neutrophils. $N$. Engl. J. Med. 303:27-34.

2. Weiss, S. J., and A. F. LoBuglio. 1982. Phagocyte-generated oxygen metabolites and cellular injury. Lab. Invest. 47:5-18.

3. Weissmann, G., J. E. Smolen, and S. Hoffstein. 1978. Polymorphonuclear leukocytes as secretory organs of inflammation. $J$. Invest. Dermatol. 71:95-99.

4. Henson, P. M. 1980. Mechanisms of exocytosis in phagocytic inflammatory cells. Am. J. Pathol. 101:494-511.

5. Sacks, T., C. F. Moldow, P. R. Craddock, T. K. Bowers, and H. S. Jacob. 1978. Oxygen radicals mediate endothelial cell damage by complement-stimulated granulocytes. An in vitro model of immune vascular damage. J. Clin. Invest. 61:1161-1167.

6. Weiss, S. J., J. Young, A. F. LoBuglio, A. Slivka, and N. F. Nimeh. 1981. Role of hydrogen peroxide in neutrophil-mediated destruction of cultured endothelial cells. J. Clin. Invest. 68:714-721.

7. Harlan, J. M., P. D. Killen, L. A. Harker, G. F. Striker, and D. G. Wright. 1981. Neutrophil-mediated endothelial injury in vitro. Mechanisms of cell detachment. J. Clin. Invest. 68:1394-1403.

8. Hoover, R. L., J. M. Robinson, and M. J. Karnovsky. 1982. Superoxide production by polymorphonuclear leukocytes is inhibited by contact with endothelial cells. J. Cell. Biol. 95:10a. (Abstr.)

9. Harlan, J. M., J. D. Levine, K. S. Callahan, B. R. Schwartz, and L. A. Harker. 1984. Glutathion redox cycle protects cultured endothelial cells against lysis by extracellularly generated hydrogen peroxide. $J$. Clin. Invest. 73:706-713.

10. Fehr, J., and C. Dahinden. 1979. Modulating influence of chemotactic factor-induced cell adhesiveness on granulocyte function. J. Clin. Invest. 64:8-16.

11. Dahinden, C., and J. Fehr. 1980. Receptor-directed inhibition of chemotactic factor-induced neutrophil hyperactivity by parazolon derivatives. Definition of a chemotactic peptide antagonist. J. Clin. Invest. 66:884-891.

12. Dahinden, C., C. Galanos, and J. Fehr. 1983. Granulocyte activation by endotoxin. Part I and II. J. Immunol. 130:857-862, 863868.

13. Fehr, J., and A. Huber. 1984. Complement-induced granulocyte adhesion and aggregation are mediated by different factors: evidence for non-equivalence of the two cell functions. Immunology. 53:583593.

14. Jaffe, E. A., R. L. Nachman, C. G. Becker, and C. R. Minick. 1973. Culture of human endothelial cells derived from umbilical veins. J. Clin. Invest. 52:2745-2756.

15. Maciag, T., G. A. Hoover, M. B. Stemerman, and R. Weinstein 1981. Serial propagation of human endothelial cells in vitro. J. Cell. Biol. 91:420-426.

16. Thornton, S. C., S. N. Mueller, and E. M. Levine. 1983. Human endothelial cells: use of heparin in cloning and long term serial cultivation. Science (Wash. DC). 222:623-625.

17. Gimbrone, M. A. 1976. Culture of vascular endothelium. Prog. Hemostasis Thromb. 3:1-28.

18. Gospodarovicz, D., and G. M. Lui. 1981. Effects of substrata and fibroblast growth factor on the proliferation in vitro of bovine aortic endothelial cells. J. Cell. Physiol. 109:69-81. 
19. Fehr, J., and H. S. Jacob. 1977. In vitro granulocyte adherence and in vivo margination: two associated complement-dependent functions. J. Exp. Med. 146:641-652.

20. Danpure, H. J., S. Osman, and F. Brady. 1982. The labeling of blood cells in plasma with "11 In-tropolonate. Br. J. Radiol. 55:247249.

21. Bault, L. E. 1973. A critical point drying technique for SEM of tissue culture cells grown on plastic substratum. Scanning Electron Microsc. 6(Part III):317-324.

22. Madri, J. A. 1982. Endothelial cell-matrix interactions in hemostasis. Prog. Hemostasis Thromb. 6:1-24.

23. Rinaldo, J. E., and R. M. Rogers. 1982. Adult respiratory distress syndrome. Changing concepts of lung injury and repair. $N$. Engl. J. Med. 306:900-909.

24. MacGregor, M. M., H. M. Friedman, E. J. Macarak, and N. A. Kefalides. 1980. Virus infection of endothelial cells increases granulocyte adherence. J. Clin. Invest. 65:1469-1477.

25. Köpel, P., E. Peterhans, G. Bertoni, P. Groscurth, R. Wyler, and R. Keller. 1984. Induction of chemiluminescene during interaction of tumoricidal effector cell populations and tumor cells is dependent on the presence of mycoplasma. J. Immunol. 132:2021-2029.

26. Smith, C. W., J. C. Hollers, R. A. Patrick, and C. Hassett. 1979. Motility and adhesiveness in human neutrophils. Effects of chemotactic factors. J. Clin. Invest. 63:221-229.

27. Goldstein, I. M., H. B. Kaplan, H. S. Edelson, and G. Weissmann. 1979. Ceruloplasmin. A scavenger of superoxide anion radicals. J. Biol. Chem. 254:4040-4045.

28. Babior, B. M. 1984. The respiratory burst of phagocytes. $J$. Clin. Invest. 73:599-601.

29. Borregaard, N., J. H. Schwartz, and A. I. Tauber. 1984. Proton secretion by stimulated neutrophils. Significance of hexose monophosphate shunt activity as source of electrons and protons for the respiratory burst. J. Clin. Invest. 74:455-459.

30. Vercellotti, G. M., J. McCarthy, L. T. Furcht, H. S. Jacob, and C. F. Moldow. 1983. Inflamed fibronectin: an altered fibronectin enhances neutrophil adhesion. Blood. 62:1063-1069. 